\title{
Utility of the morphometry of the maxillary sinuses for gender determination by using computed tomography
}

\section{Użyteczność morfometrii zatok szczękowych przy użyciu tomografii komputerowej w ustalaniu płci}

\author{
Suwarna Dangore-Khasbage ${ }^{A-E}$, Rahul Bhowate ${ }^{\mathrm{F}}$ \\ The Datta Meghe Institute of Medical Sciences, Wardha, India \\ A - research concept and design; $B$ - collection and/or assembly of data; $C$ - data analysis and interpretation; \\ $D$ - writing the article; $E$ - critical revision of the article; $F$ - final approval of the article
}

Address for correspondence

Suwarna Dangore-Khasbage

E-mail: dangore_suwarna@rediffmail.com

Funding sources

None declared

Conflict of interest

None declared

Received on June 7, 2018

Reviewed on 0ctober 6, 2018

Accepted on November 6, 2018

Published online on December 27, 2018

Cite as

Dangore-Khasbage S, Bhowate R. Utility of morphometry of maxillary sinuses for gender determination by using computed tomography. Dent Med Probl. 2018;55(4):411-417. doi:10.17219/dmp/99622

DOI

10.17219/dmp/99622

Copyright

○ 2018 by Wroclaw Medical University

and Polish Dental Society

This is an article distributed under the terms of the

Creative Commons Attribution Non-Commercial License

(http://creativecommons.org/licenses/by-nc-nd/4.0/)

\begin{abstract}
Background. It is impossible to use the routine skeletal parts for gender identification if the skeleton of unknown human remains is obtained in a fragmented and incomplete state. The alternative is to use other parts of the skeleton for gender identification.

Objectives. The objective of this study was to assess the utility of the morphometry of the maxillary sinuses using computed tomography (CT) for gender determination.

Material and methods. The study, approved by the institutional ethics committee, analyzed CT scans of 200 patients (100 males, 100 females). The measurement of the mediolateral (ML), superoinferior (SI) and anteroposterior (AP) dimensions, as well as of the volume and the antero-lateral (AL) angle of both the maxillary sinuses, was performed using a CT scan. Head circumference and head area were also measured on an axial image in order to evaluate the correlation between the sinus volume and the head circumference and head area.
\end{abstract}

Results. The mean of the mediolateral, superoinferior and anteroposterior dimensions, volume and AL angle of the right and left maxillary sinuses showed a statistically significant difference between males and females. Head circumference as well as head area were observed to be greater in males than in females, with a statistically significant difference. A positive correlation was observed between the volume of maxillary sinuses and the head circumference and head area on both sides and in both genders; however, it was not significant. Amongst all the parameters, the left AL angle with a 78.5\% accuracy was found to be the best discriminative parameter, followed by the right AL angle with a $73 \%$ accuracy. The overall accuracy of the maxillary sinus parameters to identify gender was $86 \%$.

Conclusions. The maxillary sinus measurements, as well as head circumference and head area are valuable parameters for sex determination in forensic medicine, with a relatively good accuracy rate. However, the prediction rate can be increased by including the AL angle of the maxillary sinus.

Key words: maxillary sinus, head circumference, head area, gender determination

Słowa kluczowe: zatoka szczękowa, obwód głowy, powierzchnia głowy, ustalanie płci 


\section{Introduction}

Identification of skeletal and decomposing human remains is one of the most difficult tasks in forensic medicine, just as determining the sex of an individual. However, if successful, sex determination eliminates $50 \%$ of the population from further consideration and assists in the collection of information for the biological profile of the unknown individual. ${ }^{1}$

It is said that the skeleton, next to the enamel of the teeth, provides important information in the identification of gender, as it is last to decompose after death. ${ }^{2}$ Though certain skeletal components, like the pelvis and sternum, are widely used in gender determination, these are sometimes recovered in a fragmented or incomplete state. ${ }^{3}$ In such cases, it is imperative to use for forensic purposes alternate areas of the skeleton, like the maxilla, since they are reported to remain intact, irrespective of the severe destruction of the skull and other bones, and can be used for identification of victims. ${ }^{4,5}$ In view of that, there are a number of studies stating the importance of maxillary sinuses in forensic medicine, especially for gender determination, where the dimensions of sinuses between males and females are compared by means of various imaging methods. ${ }^{5-14}$ The results of most of these studies suggested the utility of the maxillary sinuses in gender determination. Almost all these studies reported that the sinus measurement values (dimensions and volume) are larger in males than in females and they correlated this fact with the differences in the overall stature of males and females.

Head circumference is also a significant craniofacial criterion which can be used for gender determination, as the literature states that there is a strong association between head circumference and body size. ${ }^{15,16}$ Thus, the correlation between the volume of the maxillary sinus and the head circumference can provide additional information with regard to the utility of the maxillary sinuses in gender determination.

Computed tomography $(\mathrm{CT})$ scans provide an accurate assessment of the paranasal sinuses, craniofacial bones, as well as the extent of pneumatization of the sinuses. ${ }^{4-6,17}$ Furthermore, the image represents a series of contiguous cross-sections and 3-dimensional information, and the necessary equipment is available in most hospitals. Therefore, the present study was designed to assess the utility of the morphometry of the maxillary sinuses using CT for gender determination.

\section{Material and methods}

This retrospective study, approved by the institutional ethics committee (at the Datta Meghe Institute of Medical Sciences, Wardha, India), analyzed CT scans of 200 patients.

The inclusion criteria were as follows: CT scans of patients above 20 years of age, irrespective of gender, and with both sinuses shown completely. On the other hand, the exclusion criteria were: 1 . CT scans with artifacts impeding the assessment of sinuses; 2. CT scans depicting a craniofacial anomaly or conditions affecting midfacial development; 3 . CT scans with any anatomic variation that might affect the sinus volume, like nasal septal deviation $^{18,19}$; and 4. CT scans exhibiting signs of sinus pathologies or a surgical defect in the area of interest.

Maxillary sinus hypoplasia is an uncommon pathology of the paranasal sinuses, which is classified into 3 types, depending on the embryological development of the sinus, and the uncinate process might be encountered in the clinical practice. Computed tomography scans confirm its existence and any associated anatomical anomaly and variations that might coexist. ${ }^{20,21}$ Computed tomography scans depicting sinus hypoplasia were not included in the present study.

Axial and coronal images were obtained using a spiral CT scanner (Siemens Healthineers, Erlangen, Germany) with a scan setting of $140 \mathrm{kV}$ (peak), $129 \mathrm{mAs}$, scan time of $1,000 \mathrm{~ms}$ and matrix size of $512 \times 512$ pixels. During the selection of CT scans for the study, the uniformity regarding all the parameters relevant to $\mathrm{CT}$ scan imaging was ensured, namely, a uniform position of patients, 120-kV tube voltage and 175-mAs current-time product, tube rotation time, pitch, acquisition collimation, field of view in diameter, slice thickness, etc. Plain CT scans were used in the present study. On the contrary, the contrast-enhanced CT scans showing evidence of pathology were not included in the study.

The study was designed to measure the mediolateral $(\mathrm{ML})$, superoinferior (SI) and anteroposterior (AP) dimensions, along with the volumes of both the right and the left maxillary sinuses of an individual using CT. The measurements were taken after analyzing different slices in axial and coronal sections.

- the AP dimension was measured on an axial reconstructed image and was defined as the longest distance antero-posteriorly from the most anterior point to the most posterior point (Fig. 1);

- the SI dimension or the height of the sinus was measured on a coronal reconstructed image and was defined as the longest distance from the lowest point of the sinus floor to the highest point of the sinus roof (Fig. 2);

- the ML dimension or the width of the sinus was measured on an axial reconstructed image and was defined as the longest distance perpendicular from the median wall of the sinus to the outermost point of the lateral wall of the maxillary sinus (Fig. 1).

The volume of the sinuses was calculated using a simple formula described by Sahlstrand-Johnson et al. ${ }^{17}$ :

$($ ML dimension $\times$ SI dimension $\times$ AP dimension $) / 2$

where:

ML dimension - mediolateral dimension;

SI dimension - superoinferior dimension;

AP dimension - anteroposterior dimension. 


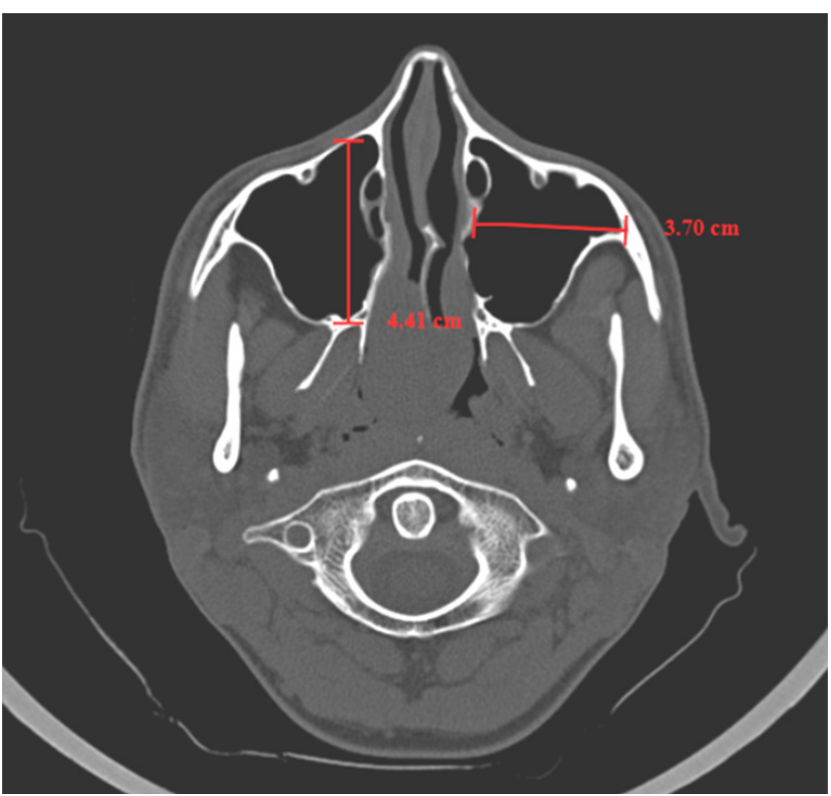

Fig. 1. Axial computed tomography (CT) scan showing the measurement of the anteroposterior (AP) and mediolateral (ML) dimensions

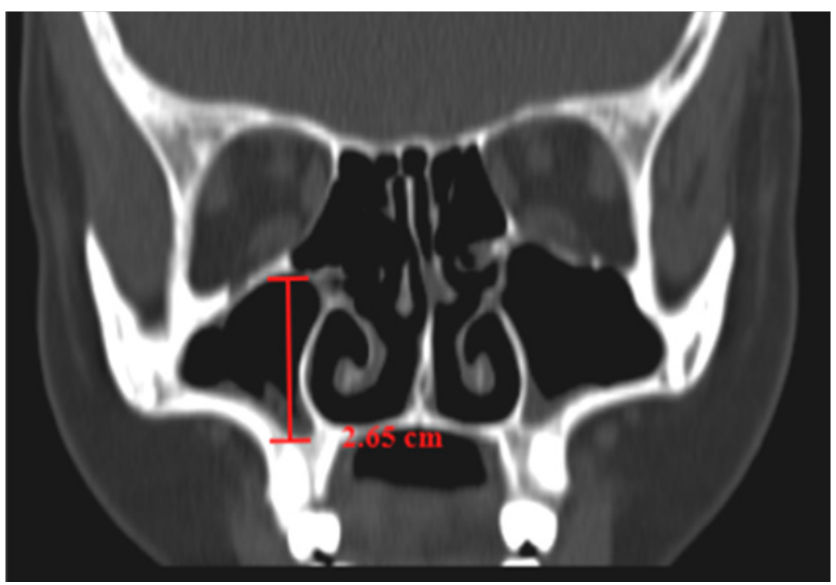

Fig. 2. Coronal CT scan showing the measurement of the superoinferior (SI) dimension

Considering the differences in the midfacial contour between males and females, such as malar prominence in females, the present study assessed and compared the angle formed by the anterior and lateral wall of the maxillary sinuses on an axial view, named the antero-lateral (AL) angle (Fig. 3). Head circumference and head area were also measured in the present study on an axial image in order to evaluate the correlation between the sinus volume and the head circumference and head area (Fig. 4). All these measurements were made with the help of a screen linear measurement tool on the CT workstation.

The data thus obtained was then tabulated and statistically analyzed using relevant statistical tests, and the software - SPSS v. 22 (IBM, Armonk, USA), GraphPad Prism ${ }^{\mathrm{TM}}$ v. 6.01 (GraphPad Software, Inc., San Diego, USA) and Epi Info $^{\mathrm{TM}}$ v. 6.0 (https://www.cdc.gov/epiinfo/support/downloads/previous/ei6.html). The independent samples $t$-test was used to determine the mean, standard deviation (SD) and $t$-value, necessary to assess the level of the parameters

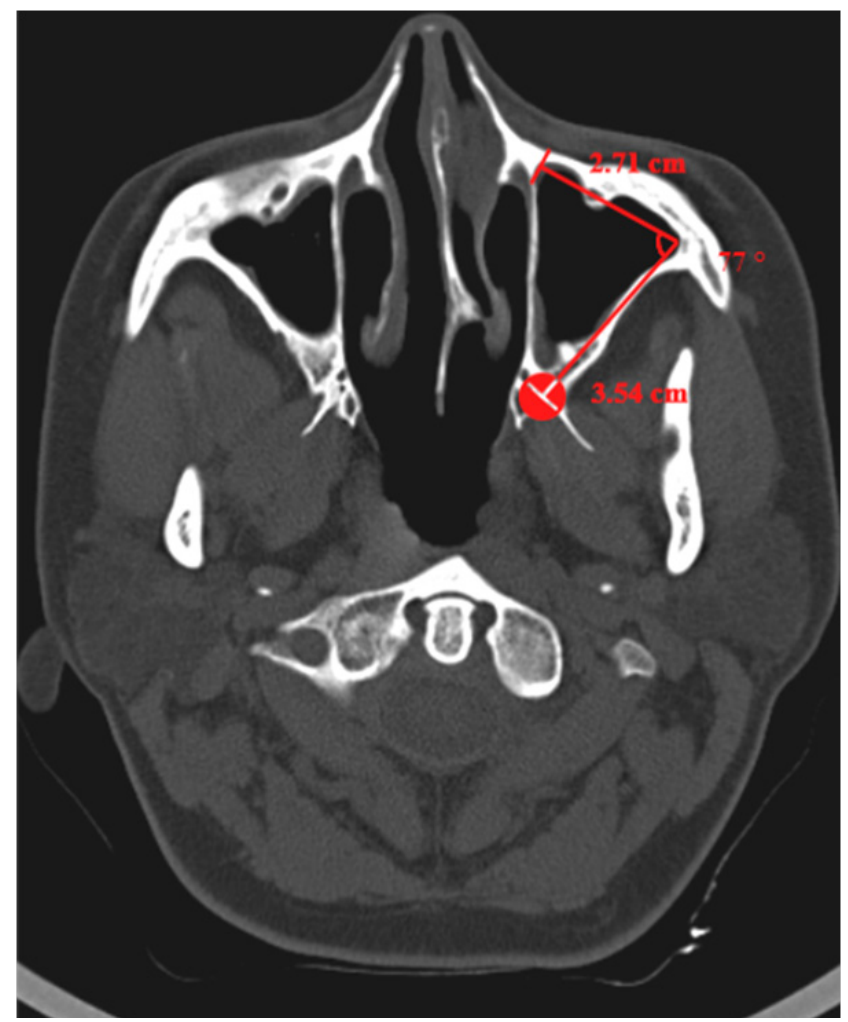

Fig. 3. Measurement of the antero-lateral (AL) angle of the maxillary sinus

in males and females. A difference at $p<0.05$ was considered significant. A discriminant function analysis was done to determine the percentage of correctly sexed maxillary sinuses.

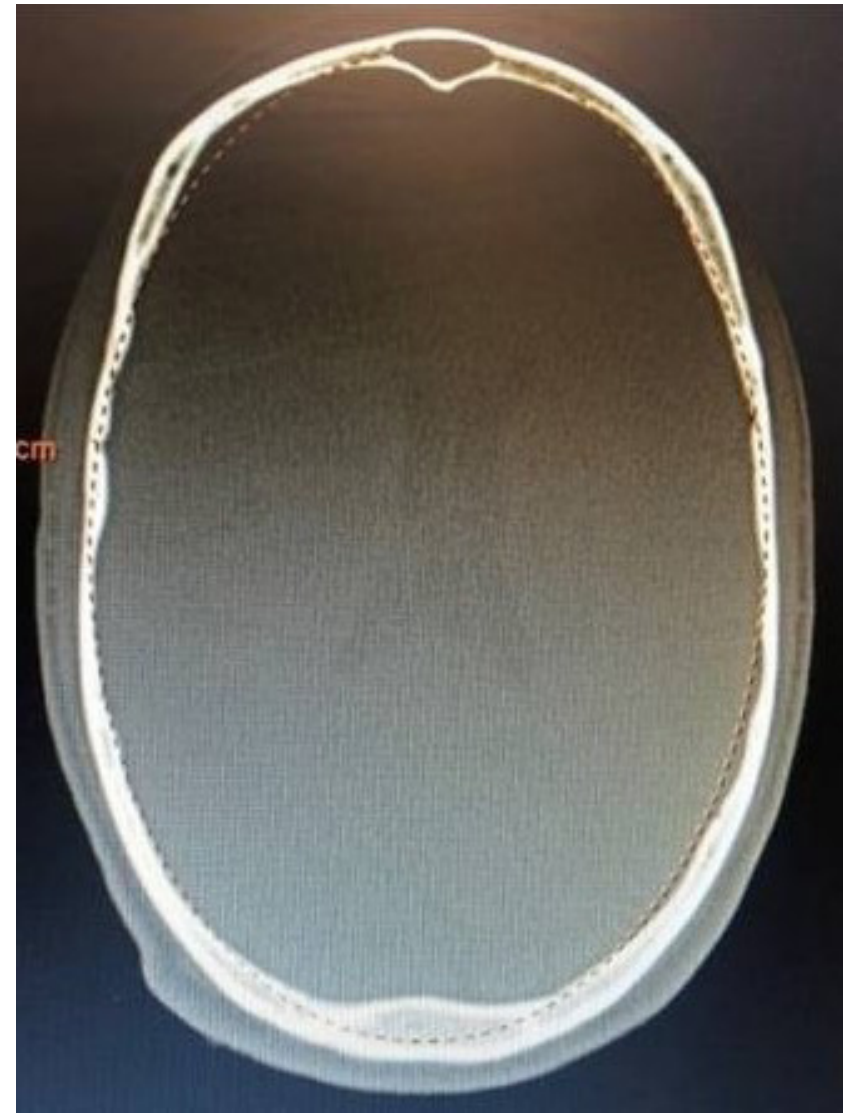

Fig. 4. Measurement of head circumference 


\section{Results}

The present study assessed CT scans of 200 patients, with equal distribution amongst males and females. In males, most of the CT scans (49\%) belonged to the patients of the age group of 20-30 years and in females, $42 \%$ CT scans were of the 41-50 years age group.

Comparative evaluation of various parameters of the right maxillary sinus between males and females, such as the mean of AP, ML and SI dimensions, as well as the volume and AL angle of the right maxillary sinuses, presented a statistically significant difference with a $p$-value of 0.0001 , as shown in detail in Table 1 . The mean volume of the right maxillary sinuses was $17.21 \pm 6.26 \mathrm{~cm}^{3}$ in males, while for females it was $11.58 \pm 4.90 \mathrm{~cm}^{3}$. In males, the mean AL angle was $76.25 \pm 9.18^{\circ}$ and in females it was $69.74 \pm 7.25^{\circ}$, showing a statistically significant difference between the genders (Fig. 5).

The study showed similar results for various parameters of the left maxillary sinus. In males, the mean $\mathrm{AL}$ angle was $82.50 \pm 17.02^{\circ}$ and in females it was $71.68 \pm 8.36^{\circ}$ (Fig. 5). Detailed observations referring to all the parameters of the left maxillary sinus are shown in Table 2.

Again, with reference to the assessment of the head circumference and head area, a statistically significant difference was observed between males and females in the mean values. In males, the mean head circumference was $46.07 \pm 1.54 \mathrm{~cm}$, while in females the mean was $44.26 \pm 1.52 \mathrm{~cm}$. For the head area, the mean was $164.51 \pm 10.73 \mathrm{~cm}^{2}$ for males and for females it was $9.19 \pm 0.91 \mathrm{~cm}^{2}$, with a $t$-value of 8.30 and 10.38 for the head circumference and head area, respectively (Fig. 6).

The overall comparative results of all the parameters assessed in the present study showed that females had significantly smaller values for all parameters as compared to males. To establish the correlation between the sinus volume and the head circumference and head area, the Pearson correlation coefficient was calculated. A positive correlation was observed between the volume of the max-

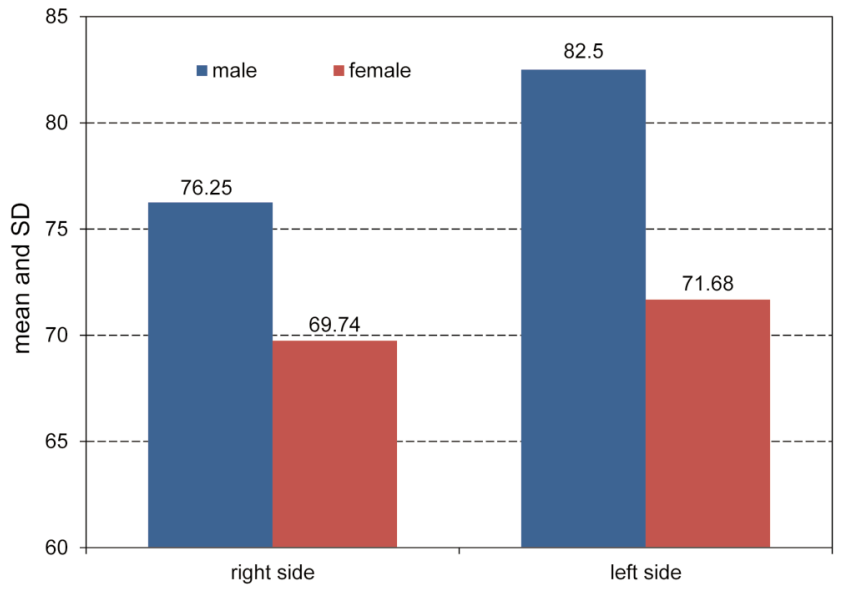

Fig. 5. Comparison of the mean AL angle between males and females

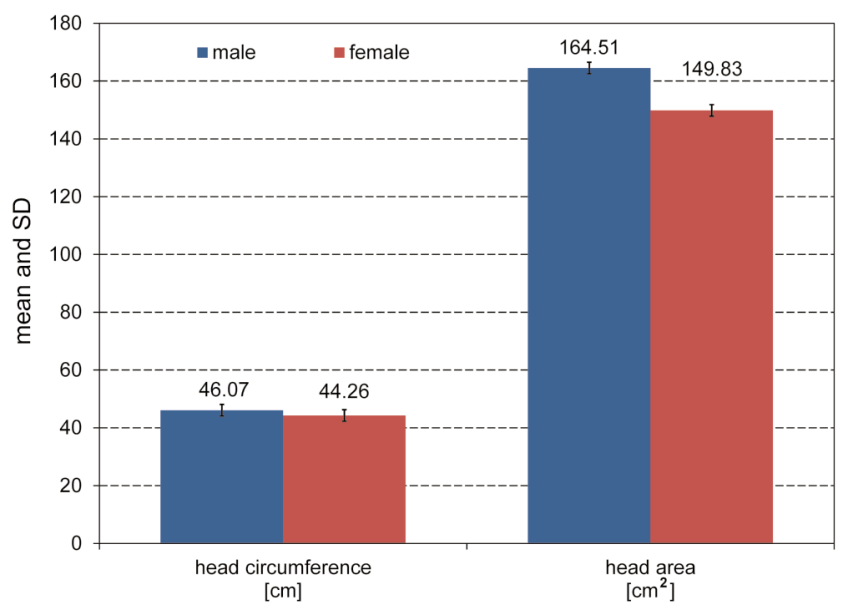

Fig. 6. Comparison of the mean head circumference and head area between males and females

illary sinuses and the head circumference and head area on both sides and in both genders; however, it was not significant. The findings suggest that the volume of the sinuses is directly proportional to the head circumference and head area in males as well as in females.

Table 1. Comparison of different parameters of the right maxillary sinuses between males and females (Student's unpaired $t$-test)

\begin{tabular}{|c|c|c|c|c|c|c|c|}
\hline Parameter & Gender & Number & Mean & SD & SEM & $t$-value & $p$-value \\
\hline \multirow{2}{*}{$\begin{array}{l}\text { AP dimension } \\
{[\mathrm{cm}]}\end{array}$} & M & 100 & 3.67 & 0.35 & 0.03 & \multirow{2}{*}{4.05} & \multirow{2}{*}{$0.0001^{*}$} \\
\hline & $\mathrm{F}$ & 100 & 3.47 & 0.34 & 0.03 & & \\
\hline \multirow{2}{*}{$\begin{array}{l}\text { ML dimension } \\
{[\mathrm{cm}]}\end{array}$} & $M$ & 100 & 2.78 & 0.47 & 0.04 & \multirow{2}{*}{5.74} & \multirow{2}{*}{$0.0001^{*}$} \\
\hline & $\mathrm{F}$ & 100 & 2.42 & 0.42 & 0.04 & & \\
\hline \multirow{2}{*}{$\begin{array}{l}\text { SI dimension } \\
{[\mathrm{cm}]}\end{array}$} & M & 100 & 3.30 & 0.92 & 0.09 & \multirow{2}{*}{5.55} & \multirow{2}{*}{$0.0001^{*}$} \\
\hline & F & 100 & 2.66 & 0.68 & 0.06 & & \\
\hline \multirow{2}{*}{$\begin{array}{l}\text { Volume } \\
{\left[\mathrm{cm}^{3}\right]}\end{array}$} & $M$ & 100 & 17.21 & 6.26 & 0.62 & \multirow{2}{*}{7.07} & \multirow{2}{*}{$0.0001^{*}$} \\
\hline & $\mathrm{F}$ & 100 & 11.58 & 4.90 & 0.49 & & \\
\hline \multirow{2}{*}{$\begin{array}{l}\text { AL angle } \\
{\left[^{\circ}\right]}\end{array}$} & $M$ & 100 & 76.25 & 9.18 & 0.91 & \multirow{2}{*}{5.56} & \multirow{2}{*}{$0.0001^{*}$} \\
\hline & $\mathrm{F}$ & 100 & 69.74 & 7.25 & 0.72 & & \\
\hline
\end{tabular}

M - male; F - female; SD - standard deviation; SEM - standard error of mean; * statistical significance. 
Table 2. Comparison of different parameters of the left maxillary sinuses between males and females (Student's unpaired t-test)

\begin{tabular}{|c|c|c|c|c|c|c|c|}
\hline Parameter & Gender & Number & Mean & SD & SEM & $t$-value & $p$-value \\
\hline \multirow{2}{*}{$\begin{array}{l}\text { AP dimension } \\
{[\mathrm{cm}]}\end{array}$} & $M$ & 100 & 3.56 & 0.63 & 0.06 & \multirow{2}{*}{2.21} & \multirow{2}{*}{$0.028^{*}$} \\
\hline & $\mathrm{F}$ & 100 & 3.39 & 0.36 & 0.03 & & \\
\hline \multirow{2}{*}{$\begin{array}{l}\text { ML dimension } \\
{[\mathrm{cm}]}\end{array}$} & M & 100 & 2.73 & 0.58 & 0.05 & \multirow{2}{*}{6.45} & \multirow{2}{*}{$0.0001^{*}$} \\
\hline & $\mathrm{F}$ & 100 & 2.25 & 0.47 & 0.04 & & \\
\hline \multirow{2}{*}{$\begin{array}{l}\text { SI dimension } \\
{[\mathrm{cm}]}\end{array}$} & $M$ & 100 & 3.33 & 0.62 & 0.06 & \multirow{2}{*}{6.93} & \multirow{2}{*}{$0.0001^{*}$} \\
\hline & $\mathrm{F}$ & 100 & 2.66 & 0.74 & 0.07 & & \\
\hline \multirow{2}{*}{$\begin{array}{l}\text { Volume } \\
{\left[\mathrm{cm}^{3}\right]}\end{array}$} & M & 100 & 16.46 & 6.39 & 0.63 & \multirow{2}{*}{6.99} & \multirow{2}{*}{$0.0001^{*}$} \\
\hline & $F$ & 100 & 10.77 & 5.03 & 0.50 & & \\
\hline \multirow{2}{*}{$\begin{array}{l}\text { AL angle } \\
{\left[^{\circ}\right]}\end{array}$} & M & 100 & 82.50 & 17.02 & 1.70 & \multirow{2}{*}{5.70} & \multirow{2}{*}{$0.0001^{*}$} \\
\hline & F & 100 & 71.68 & 8.36 & 0.83 & & \\
\hline
\end{tabular}

* statistical significance.

Table 3. Classification function coefficient and accuracy level for each parameter in determining gender

\begin{tabular}{|c|c|c|c|c|c|}
\hline \multirow{2}{*}{ Parameter } & \multicolumn{2}{|c|}{ Male } & \multicolumn{2}{|c|}{ Female } & \multirow{2}{*}{$\begin{array}{l}\text { Percentage of correctly } \\
\text { classified gender [\%] }\end{array}$} \\
\hline & constant & coefficient & constant & coefficient & \\
\hline Right - AP & -56.05 & 64 & -50.18 & 64 & 64 \\
\hline Right - ML & -19.74 & 65 & -15.06 & 71 & 68 \\
\hline Right - SI & -8.88 & 70 & -6.01 & 63 & 66.5 \\
\hline Right - volume & -5.38 & 59 & -2.81 & 69 & 64 \\
\hline Right - AL angle & -43.12 & 68 & -36.18 & 78 & 73 \\
\hline Left - AP & -24.08 & 67 & -21.99 & 47 & 57 \\
\hline Left - ML & -14.03 & 54 & -9.73 & 68 & 61 \\
\hline Left - SI & -12.38 & 73 & -8.12 & 70 & 71.5 \\
\hline Left - volume & -4.78 & 59 & -2.44 & 67 & 63 \\
\hline Left - AL angle & -19.61 & 76 & -14.98 & 81 & 78.5 \\
\hline
\end{tabular}

The classification function coefficient and the accuracy level for each parameter of the maxillary sinus on both sides in determining gender is depicted in Table 3. Amongst all the parameters, the left $\mathrm{AL}$ angle with $78.5 \%$ accuracy was found to be the best discriminative parameter, followed by the right AL angle with $73 \%$ accuracy.

The classification function coefficient and the accuracy level for the head circumference and head area in determining gender was $69 \%$ and $76 \%$, respectively.

The final result of the discriminative analysis showed that the potential of the maxillary sinus in identifying gender was $85 \%$ in males and $87 \%$ in females, with an overall accuracy of $86 \%$, as shown in Table 4 .

The accuracy of the final model in determining gender for the head circumference and head area was $73 \%$ in males and $76 \%$ in females, with an overall accuracy of $74.5 \%$.

Table 4. Accuracy of the final model in determining gender for the maxillary sinus

\begin{tabular}{|c|c|c|c|c|}
\hline \multirow{2}{*}{$\begin{array}{l}\text { Actual } \\
\text { gender }\end{array}$} & \multicolumn{2}{|c|}{ Male } & \multirow{2}{*}{ Total } & \multirow{2}{*}{$\begin{array}{l}\text { Percentage of correctly } \\
\text { classified gender [\%] }\end{array}$} \\
\hline & male & female & & \\
\hline Male & 85 & 15 & 100 & \multirow{3}{*}{86} \\
\hline Female & 13 & 87 & 100 & \\
\hline Total & 98 & 102 & 200 & \\
\hline
\end{tabular}

\section{Discussion}

Gender determination of skull remnants is an essential step in the identification of an unknown person. The present study assessed the utility of the maxillary sinuses for that purpose. The comparative assessment of the parameters of the right and left sides of the maxillary sinuses showed statistically significant differences for all the parameters, and the findings are comparable to the previous studies. 5,10,12,14,22,23 Amongst all analyzed parameters, the left AL angle with an accuracy of $78.5 \%$ was the best discriminative parameter, followed by the right $\mathrm{AL}$ angle. To our knowledge, the AL angle measurement has not been previously estimated, and thus its significance has not been reported yet.

The AL angle is an angle formed between the anterior and lateral wall of the maxillary sinus and was named by the authors as the antero-lateral (AL) angle. The reason behind the selection of this angle for gender comparison was the suspicion that there could be a difference in this angle between males and females, just as there is a difference in the midfacial contour between men and women. For example, females have a prominent molar region. The researchers thought that if the difference was significant, the AL angle might be used as an additional parameter in gender determination. 
The presence of a statistically highly significant difference between males and females in the AL angle of the right and left side maxillary sinuses, as well as the maximal final accuracy level for angle criteria in the present study suggest that the AL angle of the maxillary sinus can be used in gender determination for forensic purposes. The reason for a greater $\mathrm{AL}$ angle in males could be the overall larger size of the maxillary sinus as compared to females. The findings of this study are considered distinctive.

In the present study, amongst the remaining parameters of the maxillary sinus, the left SI dimension was the best discriminative parameter next to the AL angle. Similarly, previous studies mentioned various parameters of the maxillary sinus to be the best discriminants in their studies, some of which are depicted in Table 5.

In a review article by Xavier et al., it is concluded that the frontal and maxillary sinuses provide important information in the forensic context and, in the case of the maxillary sinus, allow for sex determination. ${ }^{24}$

On the contrary, Saccucci et al. stated that it was impossible to support the use of the maxillary sinuses to discern sexual differences in corpse identification by means of cone beam CT. ${ }^{11}$ Also, the results of the study by Etemadi et al. ${ }^{25}$ showed that the volume of the maxillary sinus could not serve as a definite and reliable indicator for sexual determination. ${ }^{25}$

The overall results of the present study showed that the dimensions and volume of the maxillary sinuses were greater in males; this finding is comparable to many previous studies, and thus can be used for gender determination as mentioned above. The common parameter for sexual difference mentioned in the literature is a bigger body size in males in comparison to females. Males tend to exhibit larger, more robust features, which can be seen throughout the cranial and post-cranial skeleton. Females tend to retain more of the pedomorphic traits throughout development. ${ }^{26}$

Sahlstrand-Johnson et al. suggested that, since men are generally larger than women, men have larger sinuses, and thus the difference in volume between males and females exists. ${ }^{17}$ Sharma et al. correlated the difference in the maxillary sinus dimensions between the genders with the physiological changes in the nasal cavity size and shape, which occur as a direct result of respiration-related needs. ${ }^{5}$

The present study draws attention to the fact that, although men are generally larger than women, this rule is not always applicable. There can be a strong, stout, tall female and, by contrast, a short, thin, average built male. Considering this fact, the authors attempted to correlate the volume of the sinuses with the head circumference, as the literature states that there is a strong association between the head circumference and body size..$^{15,16}$ It was not possible to correlate the volume of the sinuses with the height, weight and body size of the patients in the present study, as this study was retrospective. The Pearson correlation between the mean volume of the sinuses and the head circumference was assessed in terms of sig-
Table 5. Best discriminative maxillary sinus parameters in previous studies with their accuracy level

\begin{tabular}{|l|c|c|}
\hline \multicolumn{1}{|c|}{ Authors } & $\begin{array}{c}\text { Maxillary sinus } \\
\text { parameters }\end{array}$ & $\begin{array}{c}\text { Accuracy level } \\
{[\%]}\end{array}$ \\
\hline Urooge et al. $^{27}$ & left width & 60 \\
\hline Uthman et al. & height & 71.6 \\
\hline Attia et al. ${ }^{8}$ & right height & 69.9 \\
Ahmed et al. $^{10}$ & left width & 61.3 \\
\hline Sharma et al. ${ }^{5}$ & AP dimension & 69.81 \\
\hline
\end{tabular}

nificance. A positive correlation was observed between the volume of the maxillary sinuses of both sides and in both genders and the head circumference and head area. Still, the correlation was not significant.

Based on all the parameters used, the overall accuracy rate in terms of determining the sex by means of maxillary sinus measurements was $86 \%$ (85\% in males and $87 \%$ in females) in the present study. The results are comparable to those presented in a study by Prabhat et al., ${ }^{6}$ in which the overall accuracy rate was $83.3 \%$. In a similar study by Bangi et al., it was $88 \%{ }^{14}$ However, in most of the previous studies, the percentage was comparatively low. ${ }^{4,7,9,13,26,27}$ In the studies by Teke et al. and Kiruba et al., the overall accuracy rate was below $70 \%{ }^{4,28}$ The reasons for these variations are multiple and may include such factors as different ethnic and racial groups, genetic and environmental factors, differences in the body stature, skeletal size, height, etc. Besides, the anatomical variations of the sinus, differences in osteoclastic and osteoblastic activity and in the pneumatization process in the sinus in different age and sex groups, or past infections may influence the results.

The final result of the discriminative analysis showed that the efficiency of using the head circumference and head area to identify gender was $73 \%$ in males and $76 \%$ in females, with an overall accuracy of $74.5 \%$.

To our knowledge this is the first report mentioning the significance of the AL angle of the maxillary sinus, head circumference and head area in sexual determination. There is scope for further research on these new parameters for sex determination. The authors mention 1 possible limitation of this study; as the study was retrospective, it was not possible to establish a direct correlation between the volume of the sinuses and the body size of the participants.

\section{Conclusions}

The maxillary sinus measurements, as well as head circumference and head area, are valuable parameters for sex determination in forensic medicine, with a relatively good accuracy rate. However, the prediction rate can be increased by including the AL angle of the maxillary sinus. The overall accuracy of using the maxillary sinus to identify gender was $86 \%$. 


\section{References}

1. Christensen AM, Passalacqua NV, BartelinkEJ. Forensic Anthropology: Current Methods and Practice. San Diego, CA: Elsevier Academic Press; 2014:199-220.

2. Deshmukh AG, Deversh DB. Comparison of cranial sex determination by univariate and multivariate analysis. J Anat Soc India. 2006;55:1-5

3. Singal K. Significance of radiology forensic identification. $A R C$ J Forensic Sci. 2016;1:21-24.

4. Teke HY, Duran S, Canturk N, Canturk G. Determination of gender by measuring the size of the maxillary sinuses in computerized tomography scans. Surg Radio Anat. 2007;29:9-13.

5. Sharma SK, Jehan M, Kumar A. Measurements of maxillary sinus volume and dimensions by computed tomography scan for gender determination. J Anat Soc India. 2014;63:36-42.

6. Prabhat M, Rai S, Kaur M, Prabhat K, Bhatnagar P, Panjwani S. Computed tomography-based forensic gender determination by measuring the size and volume of the maxillary sinuses. J Forensic Dent Sci. 2016;8:40-46.

7. Uthman AT, Al-Rawi NH, Al-Naaimi AS, Al-Timimi JF. Evaluation of maxillary sinus dimensions in gender determination using helical CT scanning. J Forensic Sci. 2011:56:403-408.

8. Attia AM, El-Badrawy AM, Shebel HM. Gender identification from maxillary sinus using multi-detector computed tomography. Mansoura J Forensic Med Clin Toxicol. 2012;20:17-28.

9. Ekizoglu O, Inci E, Hocaoglu E, Sayin I, Kayhan FT, Can IO. The use of maxillary sinus dimensions in gender determination: A thinslice multi-detector computed tomography-assisted morphometric study. J Craniofac Surg. 2014;25:957-960.

10. Ahmed A, Gataa AG, Fateh IS, Salah MM Ghadah N. CT scan images analysis of maxillary sinus dimensions as a forensic tool for sexual and racial detection in a sample of Kurdish population. Euro Sci J. 2015;11:271-281.

11. Saccucci M, Cipriani F, Carderi S, et al. Gender assessment through three-dimensional analysis of maxillary sinuses by means of cone beam computed tomography. Eur Rev Med Pharmacol Sci. 2015;19:185-193.

12. Dkhar W, Pradhan A, Shajan M. Measurement of different dimension of maxillary and frontal sinus through computed tomography. Online J Health Allied Scs. 2017;16:5.

13. Paknahad M, Shahidi S, Zarei Z. Sexual dimorphism of maxillary sinus dimensions using cone-beam computed tomography. J Forensic Sci. 2017:62:395-398.

14. Bangi BB, Ginjupally U, Nadendla LK, Vadla B. 3D evaluation of maxillary sinus using computed tomography: A sexual dimorphic study. Int J Dent. 2017;2017:9017078.

15. Mansur DI, Haque MK, Sharma K, Mehta DK, Shakya R. Use of head circumference as a predictor of height of individual. Kathmandu Uni Med J. 2014;12:89-92.

16. Geraedts EJ, Dommelen PV, Caliebe J, et al. Association between head circumference and body size. Horm Res Paediatr. 2011;75:213-219.

17. Sahlstrand-Johnson $P$, Jannert $M$, Strömbeck A, Abul-Kasim K. Computed tomography measurements of different dimensions of maxillary and frontal sinuses. BMC Med Imag. 2011;11:8.

18. Kapusuz GZ, Ozkırış M, Okur A, Karaçavuş S, Saydam L. The effect of nasal septal deviation on maxillary sinus volumes and development of maxillary sinusitis. Eur Arch Otorhinolaryngol. 2013;270:3069-3073.

19. Jadia S, Qureshi S, Agrawal S, Singh SG. Effect of deviated nasal septum on maxillary sinus volume and occurrence of sinusitis. Ind J Otolaryngol Head Neck Surgery. 2018. https://doi.org/10.1007/ s12070-018-1276-9

20. Erdem T, Aktas D, Erdem G, Miman MC, Ozturan O. Maxillary sinus hypoplasia. Rhinology. 2002;40:150-153.

21. Hasan HYA, Prabhu S, Mohammed MA. Hypoplastic maxillary antra. Bahrain Med Bull. 2017;39:150-153.

22. Kim DI, Lee UY, Park SO, Kwak DS, Han SH. Identification using frontal sinus by three dimensional reconstruction from computed tomography. J Forensic Sci. 2012;58:5-11.

23. Michel J, Paganeli A, Varoquaux A, et al. Determination of sex: Interest of frontal sinus 3D reconstructions. J Forensic Sci. 2015;60:269-273.

24. Xavier TA, Sayuri Silveira Dias Terada A, Alves da Silva RH. Forensic application of the frontal and maxillary sinuses: A literature review. J Forensic Radiol Imaging. 2015;3:105-110.
25. Etemadi S, Seylavi G, Yadegari A. Correlation of the maxillary sinus volume with gender and some of craniofacial indices using cone beam computed tomography. Biosci Biotech Res Comm. 2017;10:580-586.

26. Krishan K, Chatterjee PM, Kanchan T, Kaur S, Baryah N, Singh RK. A review of sex estimation techniques during examination of skeletal remains in forensic anthropology case work. Forensic Sci Int. 2016;261:165e1-e8.

27. Urooge A, Patil BA. Sexual dimorphism of maxillary sinus: A morphometric analysis using cone beam computed tomography. J Clin Diag Res. 2017;11:ZC67-ZC70

28. Kiruba LN, Gupta C, Kumar S, D'Souza AS. A study of morphometric evaluation of the maxillary sinuses in normal subjects using computer tomography images. Arch Med Health Sci. 2014;2:12-15. 
